\title{
Incidência de ascite em frangos de corte alimentados com rações comerciais de alto nível energético ${ }^{(1)}$
}

\author{
Manoel Garcia Neto(2) e Egladson João Campos ${ }^{(3)}$
}

\begin{abstract}
Resumo - O trabalho objetivou avaliar os efeitos de diferentes rações comerciais com alto nível energético na incidência de ascite em frangos de corte. Foram utilizadas 1.200 aves de uma mesma linhagem comercial (Hubbard), distribuídas em 12 boxes, segundo um delineamento inteiramente ao acaso, com quatro tratamentos e três repetições de 100 aves cada. Os tratamentos foram constituídos por três diferentes rações comerciais trituradas (B, C e D) comparadas com o controle, uma ração farelada inicial (A), do primeiro ao $39^{\circ}$ dia de idade. Não houve diferenças entre os tratamentos quanto ao consumo, peso e ganho de peso das aves. Em relação à conversão alimentar, o tratamento $\mathrm{C}$ apresentou resultado significativamente melhor; entretanto, foi observada neste mesmo tratamento, a maior taxa de mortalidade. O maior motivo dos óbitos registrados foi a síndrome ascítica. Conclui-se que existe um favorecimento de surto de ascite pelas rações com melhor conversão alimentar nas aves.
\end{abstract}

Termos para indexação: distúrbio metabólico, aves, nutrição animal.

\section{Incidence of ascites on broilers fed with high energy level commercial rations}

\begin{abstract}
An experiment was carried out to verify the effects of different commercial rations with high energy level on the incidence of ascites on broilers. A total of 1,200 Hubbard birds were housed in 12 boxes, in a complete random design with four treatments and three replications of 100 birds in each replication. Treatments consisted of three commercial crumbled pellets diets (B, C and D), which were compared to the control (A), an initial mash diet, from up one to 39 days of broilers age. There was no significant difference between the treatments for feed consumed, body weight, and body gain of the birds. But, the feed conversion of the treatment $\mathrm{C}$ showed significantly better results. However, it was observed that this same treatment had the highest value of mortality and such high mortality percentage was caused by ascites. The results showed that the conversion feed was a very important factor on the incidence of ascites.
\end{abstract}

Index terms: metabolic disorder, poultry, animal nutrition.

\section{Introdução}

Dentro da complexidade da síndrome ascítica, podem ser observados fatores nutricionais, ambientais, e genéticos que favorecem a sua manifestação, principalmente quando o fator em questão predispõe as aves a uma hipoxia.

Assim sendo, a síndrome ascítica está correlacionada com a alta demanda de oxigênio, em vista do

\footnotetext{
(1) Aceito para publicação em 6 de novembro de 2001.

(2) Universidade Estadual Paulista, Dep. de Apoio, Produção e Saúde Animal, Caixa Postal 533, CEP 16050-680 Araçatuba, SP. E-mail: mgarcia@fmva.unesp.br

(3) Universidade Federal de Minas Gerais, Escola de Veterinária, Av. Dos 9 Engenheiros, 1144, CEP 30840-300 Belo Horizonte, MG. E-mail: metta@ prover.com.br
}

rápido crescimento das aves, sobrecarregando os pulmões e o coração, induzindo, desta forma, a falhas cardíacas, danos vasculares, hipoproteinemias, e, secundariamente, falhas renais, que resultam na retenção de eletrólitos (Julian, 1990; Maxwell et al., 1990; Scheele et al., 1991). Normalmente, qualquer condição que cause uma diminuição da quantidade de oxigênio transportado aos tecidos aumenta a velocidade de produção de eritrócito. Assim, principalmente os rins aumentam a produção do hormônio eritropoietina, o qual estimula a medula óssea a produzir mais hemácias. Portanto, com o aumento do número de hemácias no sangue (hematócrito), ocorre, por sua vez, um aumento da viscosidade hemática, dificultando ainda mais a passagem do sangue pela rede vascular pulmonar, dando lugar a uma sobrecarga adicional no ventrículo direito (Julian, 1990). 
Estas falhas cardíacas estariam ligadas, originariamente, com o déficit de oxigênio e com a descompensação metabólica entre o desenvolvimento do sistema muscular esquelético e o cardiopulmonar (Vidyadaran et al., 1987). Desta forma, são inúmeros os trabalhos de literatura a mostrar que qualquer fator que predispõe as aves à hipoxia favorece o desenvolvimento da síndrome ascítica.

Visando minimizar este problema, muitos pesquisadores têm proposto várias maneiras e medidas de diminuir a demanda metabólica dos frangos de corte, com o objetivo de reduzir a exigência do oxigênio para estas aves (Stewart et al., 1980; Stewart \& Muir, 1982).

O objetivo deste trabalho foi estudar a susceptibilidade das aves à síndrome ascítica causada por rações comerciais.

\section{Material e Métodos}

O estudo foi realizado na Empresa Agro Avícola Predileto Ltda., Amparo, SP, situada a $658 \mathrm{~m}$ de altitude. As temperaturas máxima, média e mínima registradas durante o período experimental (39 dias) foram, respectivamente: $31,5^{\circ} \mathrm{C}, 21,6^{\circ} \mathrm{C}$ e $9,0^{\circ} \mathrm{C}$.

Utilizou-se um galpão de alvenaria de 76x8 m, com tela nas laterais, com sistema de cortinas, piso de concreto, e pé-direito de 2,80 m, coberto com telhas francesas, possuindo corredor central, dividido em 48 compartimentos de $3,0 \times 3,5 \mathrm{~m}$ cada, com capacidade individual para 100 aves. $\mathrm{O}$ material utilizado como cama foram as maravalhas de madeira.

Nos dois primeiros dias, foram utilizados dois bebedouros de pressão tipo copo, com capacidade para $2 \mathrm{~L}$ de água cada um, e um comedouro tipo bandeja, de $0,3 \times 0,4 \mathrm{~m}$ em cada compartimento. No terceiro dia, incorporou-se um bebedouro pendular, o qual ficava suspenso durante a noite, e no quinto dia após o alojamento das aves, foram colocados três comedouros tubulares com capacidade para $20 \mathrm{~kg}$ de ração cada. No sétimo dia, foram retirados os bebedouros de pressão tipo copo, e no 14 dia, os comedouros tipo bandeja. Como fonte de aquecimento, foram utilizados aquecedores (campânulas) a gás, um em cada compartimento, durante os primeiros dez dias de vida das aves.

Foram utilizadas 1.200 aves de uma mesma linhagem comercial (Hubbard), distribuídas em 12 boxes.

As aves foram vacinadas no primeiro dia (no incubatório) contra as doenças de marek e bouba aviária, e contra as doenças de gumboro e newcastle, respectiva- mente, no sétimo dia e ao $14^{\circ}$ dia de vida das aves, na água de bebida.

Ao final de cada semana, as seguintes variáveis foram avaliadas: peso médio corporal, consumo de ração, conversão alimentar e taxa de mortalidade.

Todas as aves que morreram durante o experimento foram necropsiadas, sendo diagnosticadas como atacadas de síndrome ascítica as aves que apresentavam líquido ascítico na cavidade abdominal, e congestão generalizada (cianoses), além de sintomas pré-ascíticos, como dilatação ventricular direita e do hidropericárdio, e congestão vascular (Bottje et al., 1997).

Os corações classificados como normais, durante a necropsia, foram os de forma cônica, firme, e, especialmente, sem evidências de flacidez no ventrículo direito. Quanto ao fígado, considerou-se em condições normais aqueles com tamanho e cor característicos, bordas agudas e bem definidas (Teuscher et al., 1971). Durante a necropsia foram ainda observadas e identificadas as aves com evidências de edema e congestão visceral.

Quanto aos demais órgãos, principalmente os pulmões, não foram considerados como parâmetro de avaliação, em virtude de as recomendações em literatura afirmarem que para esta finalidade as aves deveriam ser necropsiadas entre os primeiros cinco minutos do sacrifício (Lopez Coello et al., 1991).

O delineamento foi o inteiramente ao acaso, e consistiu de quatro tratamentos e três repetições de 100 aves cada.

Os tratamentos foram caracterizados por três diferentes rações trituradas, comparadas com uma ração farelada, a saber: A) ração farelada inicial (controle negativo); B) ração triturada Purina; C) ração triturada Predileto; D) ração triturada Guabi.

Os programas de alimentação foram conduzidos de acordo com as recomendações do fabricante para as fases inicial e de engorda; os níveis de determinados nutrientes foram fornecidos, após análises laboratoriais, pela Empresa Predileto (Tabela 1).

A Tabela 2 apresenta a composição dos suplementos vitamínicos e minerais utilizados nas rações.

Os resultados obtidos foram submetidos à análise de variância (Snedecor \& Cochran, 1980) e as médias comparadas pelo teste de Duncan a 5\% de probabilidade.

\section{Resultados e Discussão}

O consumo médio diário de rações pelas aves foi praticamente semelhante em todas as observações semanais. Entretanto, foram constatadas variações significativas na terceira e quinta semanas, nas quais foi observado que as aves apresentaram menor consumo no tratamento $\mathrm{C}$, que estatisticamente di- 
feriu apenas do tratamento $\mathrm{B}$, em ambas as semanas (Tabela 3).

O consumo total médio das rações pelas aves, durante o período experimental, não demonstrou diferenças significativas $(\mathrm{P}>0,05)$; isso pode ser expli- cado pelo fato de as rações apresentarem seus níveis energéticos muito próximos (Tabela 1). Estes resultados, em parte, são concordantes com os obtidos por Well (1963), Barbosa (1992) e Zuniga (1992), os quais não observaram efeitos significativos no

Tabela 1. Composição centesimal de rações de frangos de corte, segundo análise laboratorial.

\begin{tabular}{|c|c|c|c|c|c|c|c|}
\hline \multirow[t]{3}{*}{ Variável } & \multicolumn{4}{|c|}{ Ração inicial } & \multicolumn{3}{|c|}{ Ração de engorda } \\
\hline & \multicolumn{2}{|c|}{ Predileto } & \multirow{2}{*}{$\begin{array}{c}\text { Guabi } \\
\text { triturada }\end{array}$} & \multirow{2}{*}{$\begin{array}{c}\text { Purina } \\
\text { triturada }\end{array}$} & \multirow{2}{*}{$\begin{array}{l}\text { Predileto } \\
\text { triturada }\end{array}$} & \multirow{2}{*}{$\begin{array}{c}\text { Guabi } \\
\text { triturada }\end{array}$} & \multirow{2}{*}{$\begin{array}{l}\text { Purina } \\
\text { triturada }\end{array}$} \\
\hline & Farelada & Triturada & & & & & \\
\hline Umidade & 11,14 & 11,78 & 11,79 & 10,95 & 10,62 & 11,96 & 11,10 \\
\hline Proteína bruta & 22,32 & 22,50 & 23,04 & 21,70 & 20,33 & 21,96 & 21,31 \\
\hline Extrato etéreo & 5,80 & 5,92 & 4,74 & 6,40 & 6,83 & 5,25 & 5,07 \\
\hline $\mathrm{ENN}^{(1)}$ & 55,70 & 54,35 & 56,33 & 56,37 & 57,19 & 56,93 & 59,00 \\
\hline Matéria mineral & 5,04 & 5,45 & 4,10 & 4,58 & 5,03 & 3,90 & 3,52 \\
\hline Cálcio & 1,35 & 1,10 & 1,35 & 1,60 & 1,35 & 1,50 & 1,50 \\
\hline Fósforo & 0,71 & 0,72 & 0,63 & 0,65 & 0,77 & 0,59 & 0,59 \\
\hline Sal & 0,39 & 0,41 & 0,49 & 0,39 & 0,45 & 0,38 & 0,34 \\
\hline $\mathrm{EM}(\mathrm{kcal} / \mathrm{kg})^{(2)}$ & $3.050,00$ & $3.050,00$ & $3.000,00$ & $3.100,00$ & $3.100,00$ & $3.000,00$ & $3.100,00$ \\
\hline
\end{tabular}

${ }^{(1)}$ Extrativo não nitrogenado. ${ }^{(2)}$ Energia metabolizável (fornecido pelo fabricante, segundo composição calculada).

Tabela 2. Composição do suplemento vitamínico e mineral das fases inicial e de engorda, por quilo de ração.

\begin{tabular}{|c|c|c|c|c|c|c|c|}
\hline \multirow[t]{3}{*}{ Componentes } & \multicolumn{4}{|c|}{ Ração inicial } & \multicolumn{3}{|c|}{ Ração de engorda } \\
\hline & \multicolumn{2}{|c|}{ Predileto } & \multirow{2}{*}{$\begin{array}{l}\text { Guabi } \\
\text { triturada }\end{array}$} & \multirow{2}{*}{$\begin{array}{c}\text { Purina } \\
\text { triturada }\end{array}$} & \multirow{2}{*}{$\begin{array}{l}\text { Predileto } \\
\text { triturada }\end{array}$} & \multirow{2}{*}{$\begin{array}{c}\text { Guabi } \\
\text { triturada }\end{array}$} & \multirow{2}{*}{$\begin{array}{l}\text { Purina } \\
\text { triturada }\end{array}$} \\
\hline & Farelada & Triturada & & & & & \\
\hline Vitamina A (UI) & 12.000 & 12.000 & 12.000 & 11.900 & 8.000 & 7.000 & 9.800 \\
\hline Vitamina D3 (UI) & 2.500 & 2.500 & 2.000 & 2.200 & 2.000 & 1.600 & 1.500 \\
\hline Vitamina E (mg) & 15,0 & 15,0 & 15,0 & 25,0 & 10,0 & $-(1)$ & - \\
\hline Vitamina K (mg) & 1,5 & 1,5 & 1,3 & 0,59 & 1,0 & 1,2 & 0,5 \\
\hline Tiamina (mg) & 1,0 & 1,0 & 1,8 & 1,0 & 1,0 & 2,0 & - \\
\hline Riboflavina (mg) & 2,0 & 2,0 & 7,0 & 9,0 & 1,5 & 4,5 & 6,0 \\
\hline Pantotenato de cálcio (mg) & 6,0 & 6,0 & 14,0 & 8,0 & 5,0 & 10,0 & 8,0 \\
\hline Niacina (mg) & 25,0 & 25,0 & 36,0 & 30,0 & 10,0 & 40,0 & 27,0 \\
\hline Piridoxina (mg) & 4,0 & 4,0 & 3,0 & 0,1 & 2,0 & 2,5 & - \\
\hline Biotina (mcg) & 50,0 & 50,0 & 50,0 & 30,0 & 25,0 & 60,0 & 19,0 \\
\hline Colina (mg) & 125,0 & 125,0 & 350,0 & 300,0 & 100,0 & 250,0 & 220,0 \\
\hline Ácido fólico (mg) & 0,73 & 0,73 & 0,55 & 0,40 & 0,36 & 0,6 & 0,29 \\
\hline Vitamina B12 (mcg) & 10,0 & 10,0 & 20,0 & 22,0 & 5,0 & 10,0 & 18,0 \\
\hline Antioxidante (mg) & 125,0 & 125,0 & 125,0 & 100,0 & 125,0 & 125,0 & 100,0 \\
\hline Antibiótico (mg) & - & - & 10,0 & 100,0 & - & 10,0 & 100,0 \\
\hline 3-nitro (mg) & - & - & 50,0 & - & - & - & - \\
\hline Violeta de genciana (mg) & - & - & 10,0 & - & - & - & - \\
\hline Coccidiostato (mg) & 125,0 & 125,0 & 125,0 & 100,0 & 100,0 & 100,0 & 100,0 \\
\hline Furazolidona (mg) & - & - & - & 50,0 & - & - & 50,0 \\
\hline Cobre (mg) & 4,0 & 4,0 & 3,0 & 70,0 & 4,0 & 8,0 & 58,0 \\
\hline Iodo (mg) & 0,3 & 0,3 & 0,4 & 1,6 & 0,17 & 1,0 & 1,3 \\
\hline Manganês (mg) & 27,0 & 27,0 & 50,0 & 95,0 & 30,0 & 60,0 & 78,0 \\
\hline Zinco (mg) & 20,0 & 20,0 & 40,0 & 70,0 & 20,0 & 65,0 & 58,0 \\
\hline Ferro (mg) & 23,0 & 23,0 & 20,0 & - & 40,0 & 50,0 & - \\
\hline Selênio (mg) & 0,13 & 0,13 & 0,1 & 0,2 & 0,1 & 0,3 & 0,15 \\
\hline Cobalto (mg) & - & - & - & - & - & 0,2 & - \\
\hline
\end{tabular}

${ }^{(1)}$ Componente ausente no suplemento vitamínico-mineral. 
consumo das diferentes formas físicas de rações, ou seja, farelada e granulada.

O peso médio das aves não apresentou variação significativa em nenhum período semanal (Tabela 3 ). Apenas foi observada uma discreta tendência de menor peso corporal nas aves arraçoadas com a ração farelada utilizada no tratamento A. Zirlis (1980), McNaughton \& Reece (1984), Barbosa (1992) e Zuniga (1992) também constataram que o peso médio corporal das aves não foi influenciado pelas rações na forma farelada e granulada.

Apenas na terceira e quarta semanas houve diferença significativa quanto ao ganho de peso, segundo o tipo de ração oferecida, pois as aves do trata- mento A, que receberam a ração farelada, foram as que apresentaram o menor ganho de peso $(\mathrm{P}<0,05)$ (Tabela 3). Todavia, as aves dos tratamentos B, C e $\mathrm{D}$, que receberam as rações trituradas, foram as que obtiveram o melhor ganho de peso na terceira e quarta semanas $(\mathrm{P}<0,05)$.

O ganho de peso total médio, durante o período experimental, não apresentou diferenças significativas em nenhuma ração. A mesma tendência observada quanto ao peso (Tabela 3) foi constatada no ganho de peso, ou seja: as aves alimentadas com a ração farelada do tratamento $\mathrm{A}$ foram as que tenderam ao menor ganho de peso, porém, sem diferir significativamente das outras aves. Esses resultados

Tabela 3. Efeito de diferentes rações comerciais no consumo, peso, ganho de peso, conversão alimentar e porcentual de mortalidade média semanal de frangos de corte durante o período experimental ${ }^{(1)}$.

\begin{tabular}{|c|c|c|c|c|c|c|c|}
\hline \multirow[t]{2}{*}{ Tratamento $^{(2)}$} & \multicolumn{6}{|c|}{ Semanas } & \multirow[t]{2}{*}{ Total } \\
\hline & $1^{\underline{a}}$ & $2^{-\underline{a}}$ & $3^{\mathrm{a}}$ & $4^{\mathrm{a}}$ & $5^{\mathrm{a}}$ & $6^{\mathrm{a}}$ & \\
\hline & \multicolumn{7}{|c|}{ Consumo médio (g) } \\
\hline $\mathrm{A}$ & $13,27 \mathrm{a}$ & $36,58 \mathrm{a}$ & $63,30 \mathrm{ab}$ & $94,39 a$ & $120,02 b$ & $138,11 \mathrm{a}$ & $2.845,30 \mathrm{a}$ \\
\hline $\mathrm{B}$ & $12,79 \mathrm{a}$ & $35,37 \mathrm{a}$ & $66,79 a$ & $102,93 a$ & $133,53 \mathrm{a}$ & $142,02 \mathrm{a}$ & $3.027,90 \mathrm{a}$ \\
\hline $\mathrm{C}$ & $12,34 \mathrm{a}$ & $34,96 a$ & $60,35 b$ & $98,51 \mathrm{a}$ & $119,47 b$ & $130,80 \mathrm{a}$ & $2.802,60 \mathrm{a}$ \\
\hline $\mathrm{D}$ & $12,33 \mathrm{a}$ & $36,49 a$ & $64,29 \mathrm{ab}$ & $100,34 \mathrm{a}$ & $127,25 \mathrm{ab}$ & $133,19 \mathrm{a}$ & $2.917,80 \mathrm{a}$ \\
\hline \multirow[t]{2}{*}{$\mathrm{CV}(\%)$} & 5,46 & 6,14 & 5,28 & 5,42 & 4,78 & 8,59 & 5,29 \\
\hline & \multicolumn{7}{|c|}{ Peso médio $(\mathrm{g})$} \\
\hline A & $105,73 a$ & $239,79 a$ & $492,89 a$ & $850,83 a$ & $1.270,06 \mathrm{a}$ & $1.514,29 \mathrm{a}$ & $1.514,29 \mathrm{a}$ \\
\hline B & $101,33 \mathrm{a}$ & $227,57 \mathrm{a}$ & $503,32 \mathrm{a}$ & $901,89 a$ & $1.375,14 \mathrm{a}$ & $1.626,18 \mathrm{a}$ & $1.626,18 \mathrm{a}$ \\
\hline $\mathrm{C}$ & $100,63 a$ & $231,06 \mathrm{a}$ & $497,79 a$ & $907,79 a$ & $1.375,14 \mathrm{a}$ & $1.633,00 \mathrm{a}$ & $1.633,00 \mathrm{a}$ \\
\hline $\mathrm{D}$ & $105,10 \mathrm{a}$ & $241,50 \mathrm{a}$ & $530,21 \mathrm{a}$ & $926,42 \mathrm{a}$ & $1.361,91 \mathrm{a}$ & $1.598,84 \mathrm{a}$ & $1.598,84 \mathrm{a}$ \\
\hline \multirow[t]{2}{*}{$\mathrm{CV}(\%)$} & 5,24 & 6,37 & 5,12 & 5,57 & 5,82 & 5,56 & 5,56 \\
\hline & \multicolumn{7}{|c|}{ Ganho de peso médio (g) } \\
\hline A & $59,73 a$ & $134,06 \mathrm{a}$ & $253,10 b$ & $357,94 b$ & $419,23 a$ & $244,23 a$ & $1.468,29 \mathrm{a}$ \\
\hline $\mathrm{B}$ & $55,80 \mathrm{a}$ & $126,24 \mathrm{a}$ & $275,75 a$ & $398,57 \mathrm{ab}$ & $473,25 a$ & $251,04 \mathrm{a}$ & $1.580,65 \mathrm{a}$ \\
\hline $\mathrm{C}$ & $55,43 a$ & $130,43 a$ & $266,63 \mathrm{ab}$ & $410,11 \mathrm{a}$ & $467,35 \mathrm{a}$ & $257,86 a$ & $1.587,79 \mathrm{a}$ \\
\hline $\mathrm{D}$ & $59,09 \mathrm{a}$ & $136,39 \mathrm{a}$ & $288,71 \mathrm{a}$ & $396,21 \mathrm{ab}$ & $435,50 \mathrm{a}$ & $236,93 \mathrm{a}$ & $1.552,83 \mathrm{a}$ \\
\hline \multirow[t]{2}{*}{$\mathrm{CV}(\%)$} & 9,77 & 8,39 & 4,76 & 7,20 & 6,88 & 9,03 & 5,73 \\
\hline & \multicolumn{7}{|c|}{ Conversão alimentar média (g consumo/g ganho) } \\
\hline A & $1,57 \mathrm{a}$ & $1,92 \mathrm{a}$ & $1,76 \mathrm{a}$ & $1,86 \mathrm{a}$ & $2,02 \mathrm{a}$ & $2,34 \mathrm{a}$ & $1,95 \mathrm{a}$ \\
\hline $\mathrm{B}$ & $1,62 \mathrm{a}$ & $1,97 \mathrm{a}$ & $1,71 \mathrm{a}$ & $1,81 \mathrm{ab}$ & $2,00 \mathrm{a}$ & $2,37 \mathrm{a}$ & $1,93 \mathrm{ab}$ \\
\hline $\mathrm{C}$ & $1,58 \mathrm{a}$ & $1,88 \mathrm{a}$ & $1,60 \mathrm{~b}$ & $1,71 b$ & $1,83 b$ & $2,19 \mathrm{a}$ & $1,80 \mathrm{c}$ \\
\hline $\mathrm{D}$ & $1,49 \mathrm{a}$ & $1,88 \mathrm{a}$ & $1,57 \mathrm{~b}$ & $1,77 \mathrm{ab}$ & $2,05 \mathrm{a}$ & $2,34 \mathrm{a}$ & $1,89 \mathrm{~b}$ \\
\hline \multirow[t]{2}{*}{$\mathrm{CV}(\%)$} & 5,85 & 6,32 & 2,61 & 3,45 & 4,05 & 8,65 & 1,66 \\
\hline & \multicolumn{7}{|c|}{ Mortalidade (\%) } \\
\hline A & $0,67 \mathrm{a}$ & $0,50 \mathrm{a}$ & $1,85 \mathrm{a}$ & $1,03 \mathrm{ab}$ & $1,74 \mathrm{ab}$ & $8,17 \mathrm{a}$ & $13,33 \mathrm{ab}$ \\
\hline $\mathrm{B}$ & $0,67 \mathrm{a}$ & $0,33 \mathrm{a}$ & $1,01 \mathrm{a}$ & $0,00 \mathrm{~b}$ & $3,75 \mathrm{a}$ & $3,53 \mathrm{ab}$ & $9,00 \mathrm{ab}$ \\
\hline $\mathrm{C}$ & $1,33 \mathrm{a}$ & $0,34 \mathrm{a}$ & $2,38 \mathrm{a}$ & $2,44 a$ & $3,58 \mathrm{a}$ & $5,26 a b$ & $14,34 \mathrm{a}$ \\
\hline $\mathrm{D}$ & $1,00 \mathrm{a}$ & $0,34 \mathrm{a}$ & $0,68 \mathrm{a}$ & $1,03 \mathrm{ab}$ & $0,69 \mathrm{~b}$ & $2,11 \mathrm{~b}$ & $5,68 \mathrm{~b}$ \\
\hline $\mathrm{CV}(\%)$ & 95,47 & 167,66 & 45,65 & 88,48 & 41,16 & 29,08 & 24,41 \\
\hline
\end{tabular}

${ }^{(1)}$ Para cada variável e para cada coluna, médias seguidas da mesma letra não diferem entre si pelo teste de Duncan a 5\% de probabilidade. (2) A: ração farelada inicial (controle negativo); B: ração triturada Purina; C: ração triturada Predileta; D: ração triturada Guabi. 
são concordantes com os obtidos por Barbosa (1992) e Zuniga (1992), mas discordam dos constatados por Crespi (1979), que verificou maior ganho de peso nos frangos alimentados com rações granuladas.

Houve melhor conversão alimentar nas aves do tratamento $\mathrm{C}$ que diferiu estatisticamente dos outros tratamentos durante a terceira, quarta e quinta semanas (Tabela 3). Pela conversão total média do período experimental, foi constatada a tendência não-significativa observada tanto no peso médio das aves como no ganho de peso, em relação ao tratamento A, que culminou em um pior índice de conversão alimentar no final do experimento, apenas não diferindo estatisticamente $(\mathrm{P}>0,05)$ das aves do tratamento B; constatou-se, também, que as aves alimentadas com o tratamento $\mathrm{C}$ obtiveram o melhor valor de conversão total médio no período experimental, e se destacaram significativamente das aves dos outros tratamentos, verificando-se, assim, um melhor desempenho das aves do tratamento $\mathrm{C}$.

Esses resultados confirmam as observações feitas por Zuniga (1992), segundo o qual o processo de granulação melhora a digestibilidade dos ingredientes das rações, já que entre as formas físicas das rações não houve diferenças significativas quanto ao consumo de ração e peso vivo das aves. Resultados semelhantes foram obtidos por Barley et al. (1967) e McNaughton \& Reece (1984); entretanto, Barbosa (1992) não encontrou respostas significativas com as diferentes formas físicas das rações, quanto à conversão alimentar.

A porcentagem de mortalidade das aves que receberam o tratamento $\mathrm{D}$ foi a menor na quinta e sexta semana do experimento (Tabela 3 ). Analogamente, no porcentual total médio do período, o tratamento D concorreu com a menor mortalidade. $\mathrm{O}$ índice de mortalidade no tratamento $\mathrm{C}$ superou em $60,4 \%$ o porcentual verificado no tratamento $\mathrm{D}$. A ração do tratamento $\mathrm{C}$, formulada para o período de inverno, incluía em sua composição o coccidicida nicarbazina, que possivelmente interagiu com a temperatura, e, conseqüentemente, favoreceu a mortalidade. Beers et al. (1989) e Wiernusz \& Teeter (1995) citam que aves alimentadas com nicarbazina são mais susceptíveis ao estresse calórico, pelo fato de seu mecanismo de ação causar um aumento na taxa de metabolismo, diminuição na freqüência respiratória, aumento na freqüência cardíaca e desenvolvimento de hipertermia mais rapidamente que nas aves não medicadas durante períodos de estresse calórico.

Os tratamentos A e B apresentaram valores intermediários quanto ao porcentual de mortalidade, em relação aos tratamentos $\mathrm{C} \mathrm{e} \mathrm{D,} \mathrm{e} \mathrm{o} \mathrm{tratamento} \mathrm{A} \mathrm{tam-}$ bém apresentava o coccidicida nicarbazina em sua formulação.

Zuniga (1992) não encontrou diferença significativa no efeito da forma física da ração em relação à taxa de mortalidade. Por outro lado, Silva et al. (1988) e Barbosa (1992), contrariando, em parte, os resultados do presente experimento, constataram grau de mortalidade altamente significativo $(\mathrm{P}<0,01)$ nas aves que consumiram rações granuladas, em relação às fareladas.

Entre as aves que morreram durante o período experimental, nenhum óbito causado pela síndrome ascítica foi constatado até a terceira semana (Tabela 4). Resultados semelhantes foram observados por Lopez Coello et al. (1991), Barbosa (1992) e Gonzales et al. (1998). Todavia, a partir da quarta semana, os primeiros casos surgiram, mas somente na sexta semana foi constatada diferença significativa, e as aves do tratamento $\mathrm{C}$ foram as que apresentaram maior incidência de ascite $(\mathrm{P}<0,05)$.

As grandes oscilações de temperatura verificadas no interior do galpão (Figura 1), culminando com uma súbita elevação no final do período experimental, muito contribuíram para agravar a incidência de mortes por síndrome ascítica, nas aves já debilitadas, na sexta semana (Tabela 4). Observações semelhantes foram relatadas por Silva (1991).

Quanto ao porcentual de mortalidade total médio do período experimental, foram também as aves do tratamento $\mathrm{C}$ que apresentaram maior índice de mortalidade pela síndrome ascítica. As aves do tratamento D apresentaram o menor porcentual de síndrome ascítica. As aves dos tratamentos A e B não diferiram entre si estatisticamente, e foram in- 
Tabela 4. Mortalidade média semanal por ascite (\%), mortalidade total por ascite (\%) e mortalidade por síndrome ascítica em relação à mortalidade total (\%), de frangos de corte alimentados com diferentes rações comerciais, em relação ao período experimental ${ }^{(1)}$.

\begin{tabular}{ccccccccc}
\hline Tratamento $^{(2)}$ & \multicolumn{9}{c}{ Semanas } & Mortalidade total & $\begin{array}{c}\text { Mortalidade pela síndrome } \\
\text { ascítica em relação à total }\end{array}$ \\
\cline { 2 - 7 } & $1^{\mathrm{a}}$ & $2^{\mathrm{a}}$ & $3^{\mathrm{a}}$ & $4^{\mathrm{a}}$ & $5^{-\mathrm{a}}$ & $6^{\mathrm{a}}$ & & $35,99 \mathrm{a}$ \\
$\mathrm{A}$ & 0,00 & 0,00 & 0,00 & $0,34 \mathrm{a}$ & $0,69 \mathrm{a}$ & $3,89 \mathrm{ab}$ & $4,67 \mathrm{ab}$ & $53,13 \mathrm{a}$ \\
$\mathrm{B}$ & 0,00 & 0,00 & 0,00 & $0,00 \mathrm{a}$ & $2,03 \mathrm{a}$ & $2,81 \mathrm{~b}$ & $4,67 \mathrm{ab}$ & $57,75 \mathrm{a}$ \\
$\mathrm{C}$ & 0,00 & 0,00 & 0,00 & $1,05 \mathrm{a}$ & $3,23 \mathrm{a}$ & $7,12 \mathrm{a}$ & $10,34 \mathrm{a}$ & $60,00 \mathrm{a}$ \\
$\mathrm{D}$ & 0,00 & 0,00 & 0,00 & $0,69 \mathrm{a}$ & $1,05 \mathrm{a}$ & $2,10 \mathrm{~b}$ & $3,69 \mathrm{~b}$ & 36,70 \\
\hline $\mathrm{CV}(\%)$ & 0,00 & 0,00 & 0,00 & 149,49 & 65,60 & 26,90 & 28,39 & \\
\hline
\end{tabular}

(1)Em cada coluna, médias seguidas da mesma letra não diferem entre si pelo teste de Duncan a 5\% de probabilidade. (2)A: ração farelada inicial (controle negativo); B: ração triturada Purina; C: ração triturada Predileta; D: ração triturada Guabi.

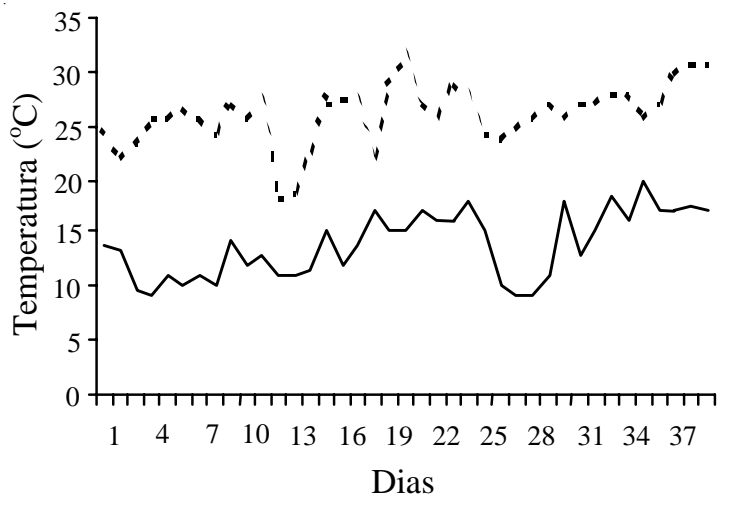

Figura 1. Temperaturas máximas (--) e mínimas (-) registradas no galpão onde o experimento foi realizado.

termediárias quanto ao porcentual de casos ascíticos, em relação às aves dos tratamentos $\mathrm{C}$ e $\mathrm{D}$.

Aproximadamente metade das aves que morreram tiveram como motivo a síndrome ascítica (Tabela 4), o que reforça os relatos de Lopez Coello et al. (1991) de que a síndrome, em algumas regiões, já representa valores em torno ou até acima de $50 \%$ de toda a mortalidade em frangos de corte, chegando a uma incidência média de $62 \%$ em alguns casos.

As aves do tratamento D apresentaram mortalidade significativamente menor; a ração deste tratamento foi a que, pela análise laboratorial, apresentou o menor teor em extrato etéreo, e, assim, o menor teor energético, o que pode ter favorecido o menor índice de mortalidade observado. A redução da inclusão de gordura (extrato etéreo) na dieta de aves na fase inicial poderia ser um dos mecanismos, visto que, no processo de oxidação, as gorduras demandam mais oxigênio que os carboidratos. Por outro lado, na fase inicial, a ave oxida praticamente toda a gordura ingerida, implicando maior necessidade de oxigênio e aumento da susceptibilidade à síndrome ascítica (Julian, 1990).

Foram encontradas lesões macroscópicas, cardíacas e hepáticas, e constatado hidropericárdio num alto porcentual de aves necropsiadas (Tabela 5). Em muitas delas, não ocorreu o acúmulo de líquido ascítico. Estes resultados indicam que, na maioria dos óbitos, as aves manifestaram, em seu quadro clínico, uma evolução gradativa para a síndrome ascítica, embora não tenham apresentado líquido ascítico em sua cavidade abdominal. Estes resultados concordam com os de Lopez Coello et al. (1991), segundo os quais nem todas as aves com síndrome ascítica apresentam líquido em quantidades consideráveis na cavidade abdominal, sobretudo nos primeiros estádios da síndrome.

A ração inicial (tratamento $\mathrm{A}$ ) foi oferecida às aves como um controle negativo, do primeiro dia de idade até o término do experimento; assim, a recomendação de evitar o excesso de proteína visando minimizar a síndrome ascítica não foi atendida, pois seu conteúdo protéico não foi alterado $(22,0 \%)$. Desta maneira, nas três últimas semanas houve um excesso protéico, o qual poderia ter refletido na tendência observada de maiores valores porcentuais para deformações cardíacas e a presença de hidropericárdio, favorecendo a incidência da síndrome ascítica. Foi constatado, ainda, que as lesões hepáticas 
Tabela 5. Exsudato ascítico líquido e gelatinoso (\%), hidropericárdio (\%), lesões cardíacas e hepáticas (\%), trato digestivo congesto $(\%)$ e total de aves necropsiadas ${ }^{(1)}$.

\begin{tabular}{|c|c|c|c|c|c|c|c|}
\hline \multirow[t]{2}{*}{ Tratamento } & \multicolumn{2}{|c|}{ Exsudato ascítico } & \multirow[t]{2}{*}{ Hidropericárdio } & \multicolumn{2}{|c|}{ Lesões } & \multirow{2}{*}{$\begin{array}{l}\text { Trato digestivo } \\
\text { congesto }\end{array}$} & \multirow{2}{*}{$\begin{array}{l}\text { Total de aves } \\
\text { necropsiadas }\end{array}$} \\
\hline & Líquido & Gelatinoso & & Cardíacas & Hepáticas & & \\
\hline A & $19,77 b$ & $17,14 \mathrm{a}$ & $73,72 a$ & $61,00 \mathrm{a}$ & $53,09 \mathrm{a}$ & $9,31 b$ & 81 \\
\hline B & $45,56 a b$ & $17,22 \mathrm{a}$ & $57,22 \mathrm{a}$ & $53,89 \mathrm{a}$ & $31,67 b$ & $36,67 \mathrm{a}$ & 28 \\
\hline $\mathrm{C}$ & $55,34 \mathrm{ab}$ & $4,62 \mathrm{a}$ & $53,28 \mathrm{a}$ & $57,38 \mathrm{a}$ & $26,95 b$ & $39,22 \mathrm{a}$ & 51 \\
\hline $\mathrm{D}$ & $64,44 \mathrm{a}$ & $14,43 \mathrm{a}$ & $64,44 \mathrm{a}$ & $57,78 \mathrm{a}$ & $23,33 b$ & $35,55 \mathrm{a}$ & 19 \\
\hline $\mathrm{CV}(\%)$ & 42,90 & 63,64 & 29,92 & 32,64 & 18,36 & 39,44 & - \\
\hline
\end{tabular}

${ }^{(1)}$ Em cada coluna, médias seguidas da mesma letra não diferem entre si a $5 \%$ de probabilidade, pelo teste de Duncan. ${ }^{(2)} \mathrm{A}$ : ração farelada inicial (controle negativo); B: ração triturada Purina; C: ração triturada Predileta; D: ração triturada Guabi.

verificadas nas aves do tratamento A diferiram estatisticamente de todas as aves arraçoadas com as demais rações, o que confirma as tendências relatadas anteriormente.

\section{Conclusões}

1. Rações comerciais apresentam diferentes graus de favorecimento à síndrome ascítica.

2. A incidência de ascite é favorecida pelas rações com melhor conversão alimentar nas aves.

\section{Referências}

BARBOSA, M. J. B. Efeitos de níveis de energia metabolizável e da forma física da ração sobre o desempenho de frangos de corte criados com separação de sexo. 1992. 86 f. Dissertação (Mestrado) - Universidade Federal de Minas Gerais, Belo Horizonte.

BARLEY, H. S.; SUMMERS, J. D.; SLINGER, S. J. The effect of steam pelleting feed ingredients on chick performance: effect of phosphorus availability, metabolizable energy value and carcass composition. Poultry Science, Champaign, v. 46, n. 5, p. 1140-1148, 1967.

BEERS, K. W.; RAUP, T. J.; BOTTJE, W. G. Physiological responses of heat-stressed broilers fed nicarbazin. Poultry Science, Champaign, v. 68, p. 428-434, 1989.

BOTTJE, W. G.; ERF, G. F.; BERSI, T. K.; WANG, S.; BARNES, D.; BEERS, K. W. Effect of dietary dl- $\alpha$ tocopherol on tissue $\alpha$ - and $\gamma$-tocopherol and pulmonary hypertension syndrome (ascites) in broilers. Poultry Science, Champaign, v. 76, n. 11, p. 1506-1512, 1997.
CRESPI, M. P. A. L. Uso de rações extrusadas na alimentação de frangos de corte. 1979. 56 f. Dissertação (Mestrado) - Universidade Federal de Minas Gerais, Belo Horizonte.

GONZALES, E.; BUYSE, J.; TAKITA, S.; SARTORI, J. R.; DECUYPERE, E. Metabolic disturbances in male broilers of different strains. 1. Performance, mortality, and right ventricular hypertrophy. Poultry Science, Champaign, v. 77, n. 11, p. 1646-1653, 1998.

JULIAN, R. J. Pulmonary hypertension: a cause of right heart failure, ascites in meat-type chickens. Feedstuffs, Minnetonka, v. 62, n. 5, p. 19-20, 22, 78, 1990.

LOPEZ COELLO, C.; MENOCAL, J. A.; GONZALES, E. A.; PELAEZ, C. V. El síndrome ascítico en pollos de engorda. In: CONFERÊNCIA APINCO DE CIÊNCIA E TECNOLOGIA AVÍCOLAS, 1991, Campinas. Anais... Campinas: Associação Brasileira de Produtores de Pintos de Corte, 1991. p. 75-96.

MAXWELL, M. H.; SPENCE, S.; ROBERTSON, G. W.; MITCHELL, M. A. Haematological and morphological responses of broiler chicks to hypoxia. Avian Pathology, Abingdon, v. 19, n. 1, p. 23-40, 1990.

McNAUGHTON, J. L.; REECE, F. N. Factors affecting pelleting response. 1. Influence of dietary energy in broiler starter diets. Poultry Science, Champaign, v. 63, n. 4, p. 682-685, 1984.

SCHEELE, C. W.; WIT, W. de; FRANKENHUIS, M. T.; VEREIJKEN, P. F. G. Ascites in broilers. 1. Experimental factors evoking symptoms related to ascites. Poultry Science, Champaign, v. 70, n. 5, p. 1069-1083, 1991.

SILVA, J. M. L. da. Ascite em frangos de corte: a situação no Brasil. In: CONFERÊNCIAAPINCO DE CIÊNCIA E TECNOLOGIA AVÍCOLAS, 1991, Campinas. Anais... Campinas: Associação Brasileira de Produtores de Pintos de Corte, 1991. p. 97-100. 
SILVA, J. M. L. da; DALE, N.; LUCHESI, J. B. Effect of pelleted feed on the incidence of ascites in broilers reared at low altitudes. Avian Diseases, Kennett Square, v. 32, n. 2, p. 376-378, 1988.

SNEDECOR, G. W.; COCHRAN, W. G. Statistical methods. 6. ed. Ames: Iowa State University Press, 1980. $507 \mathrm{p}$.

STEWART, P. A.; MUIR, W. M. The effect of varying protein levels on carcass composition and nutrient utilization in two lines of chickens divergently selected for $\mathrm{O}_{2}$ consumption. Poultry Science, Champaign, v. 61, n. 1, p. 1-11, 1982.

STEWART, P. A.; MUIR, W. M.; BEGIN, J. J.; JOHNSOW, T. H. Feed efficiency and gain responses to protein levels in two lines of birds selected for oxygen consumption. Poultry Science, Champaign, v. 59, n. 12, p. 2692-2696, 1980.

TEUSCHER, E.; LOPEZ, E. V.; ALVAREZ, R. Pathological-anatomical studies on an ascites syndrome in fattening chickens at high altitude. Zentralblatt für Veterinärmedizin, Berlin, v. 18, n. 5, p. 380-394, 1971.
VIDYADARAN, M. K.; KING, A. S.; KASSIM, H. Deficient anatomical capacity for oxygen up take of the developing lung of the female domestic fowl when compared with the red jungle fowl. Schweizer Archiv fuer Tierheilkunde, Bern, v. 129, n. 5, p. 225-237, 1987.

WELL, R. G The relationship between dietary energy level, food consumption and growth in broiler chicks. British Poultry Science, Abingdon, v. 4, n. 1, p. 161-168, 1963.

WIERNUSZ, C. J.; TEETER, R. G. Nicarbazin effects on broiler thermobalance during high ambient temperature stress. Poultry Science, Champaign, v. 74, n. 3, p. 577580, 1995.

ZIRLIS, A. E. F. Efeitos da concentração de nutrientes e forma física em dietas de acabamento para frangos de corte criados em bateria. 1980. 41 f. Dissertação (Mestrado) - Universidade Federal de Minas Gerais, Belo Horizonte.

ZUNIGA, I. O. Efeitos de programas de alimentação e forma física da ração sobre o desempenho de duas linhagens de frangos de corte. 1992. 86 f. Dissertação (Mestrado) - Universidade Federal de Minas Gerais, Belo Horizonte. 